\title{
Improving Service Operation Performance by a Cross-Industry Reference Model
}

\author{
Peter Osadsky ${ }^{1}$, Amit Garg ${ }^{1}$, Bogdan Nitu', Oliver Schneider ${ }^{2}$ \\ and Stefan Schleyer ${ }^{3}$ \\ 1 Forschungsinstitut für Rationalisierung, \\ Pontdriesch 14/16, 52062 Aachen, Germany \\ incoco@fir.rwth-aachen.de \\ http://www.fir.de \\ 2 ETH Zurich, Center for Enterprise Sciences (BWI), 8092 Zurich, \\ Switzerland \\ OSchneider@ethz.ch \\ http://www.lim.ethz.ch \\ 3 SKF GmbH, Gunnar-Wester-Str. 12, 97421 Schweinfurt \\ Stefan.Schleyer@skf.com \\ http://www.skf.com
}

\begin{abstract}
.
The importance of business related services has been growing consequently during the past years. Industrial Services constitute the greatest share of business related service with $30 \%$ of their intermediate output. But those kinds of services are facing tremendous challenges in terms of synchronizing their process with the manufacturing processes of their customers. The EU funded project InCoCo-S aims to tackle these challenges by the development of an innovative reference model for the collaboration between Service Providers and Manufacturers. Currently, the development of the structure of the reference model is finished and its validation has already begun. In this scope, $\mathrm{SKF}$, as one of the consortium partners, is currently implementing the results in their new service division - Windmill Condition Monitoring. This paper provides detailed information about conducted surveys within the InCoCo-S project, the Reference Model and its practical application.
\end{abstract}

\section{Introduction}

Business related services constitute the largest sector of the economy employing around 55 million persons in 2001 - nearly $55 \%$ of total employment in the EU market economy - and representing around $70 \%$ of EU GDP [1]. Since business related services are the dominant part of the European market economy, the 
European manufacturing industry is highly dependent on external service providers and consumes nearly $30 \%$ of the intermediate output of business related services, so called Industrial Services.

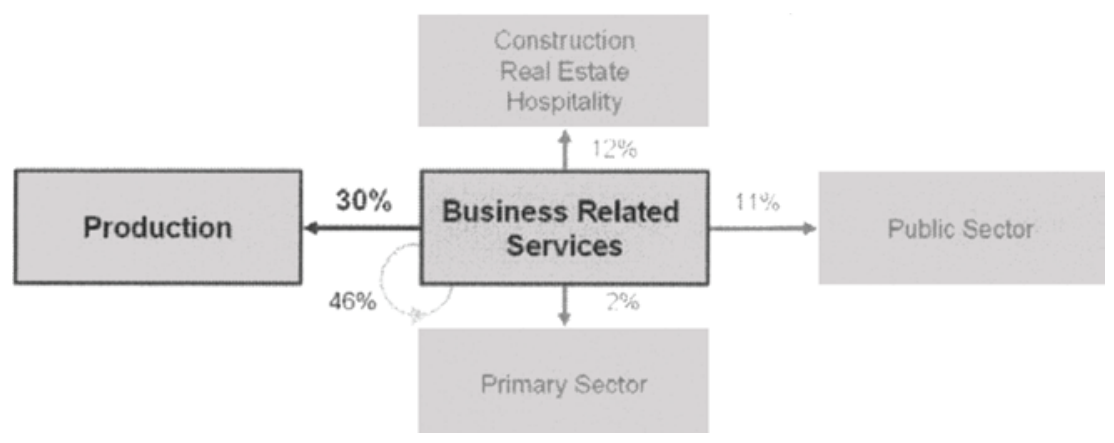

Figure 1: Key issues to be addressed from manufacturer perspective and service provider perspective [1]

Unfortunately, managers of both manufacturing and supporting service organisations are facing massive difficulties when trying to integrate and synchronize their joint activities. The key challenges for the service-supply chain can be categorized as: enabling coordination by synchronisation of business processes and information, developing metrics for measuring the performance of joint activities, advanced support for decision making and finally encapsulation of these developments into standards for the service sector.

The EU funded project "Innovation, Coordination and Collaboration in Service Driven Manufacturing Supply Chains" (InCoCo-S) takes up this challenge by developing an InCoCo-S Reference Model (IRM) for the collaboration between Service Providers and Manufacturers.

\subsection{Survey Results}

In order to get detailed requirements from the company's perspective, two surveys were designed and carried on involving 81 service providers and 81 manufacturers [2]. 

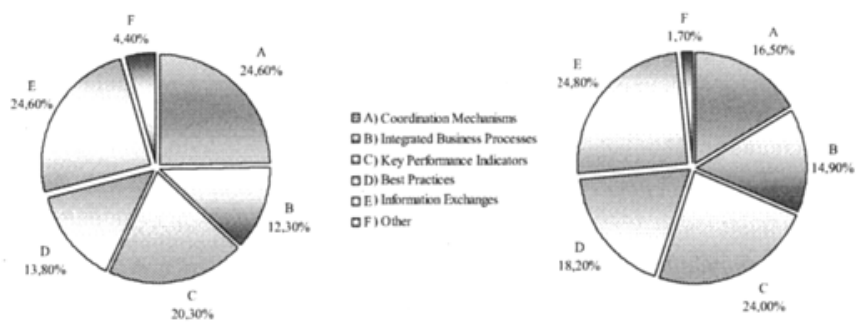

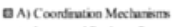

a) Binceraed Buniess Processes

DC) Key Performance Indewaor

o Di Bes Prackes

QE) linbermation Fichurge

af) Other

Figure 2: Key issues to be addressed from manufacturer perspective and service provider perspective [2]

The survey reveals key issues for the IRM. Both Manufacturers and Service Provider state great importance for Coordination Mechanisms, Performance Measurement Systems and Best-Practices.

To consider the stated aspects from the Service Provider and Manufacturer in the IRM, an appropriate framework should be used. Although being used primarily in logistics, the SCOR Model provides such a framework. But Industrial Services are regarded only as a single process element in SCOR so that it cannot be used for detailed service operations. Hence, InCoCo project aims at the development of the IRM specifically for Industrial Services, so that Service Provider and Manufacturer can cope with the aforementioned challenges in their regularly collaboration.

\subsection{Approach towards the InCoCo-S Reference Model}

The IRM was developed in several workpackages together with the industrial partners of the InCoCo-S consortium. The consortium is composed of strong inđustrial partners such as SKF, Sigpack-Bosch, SAP, Comau, Adige, Hörmann Industrietechnik, Unitech and Ventana Systems. It covers five major Industrial Services in the following domains:

- Maintenance

- Packaging

- Logistics

- Quality Control

- Retrofit

In the beginning, the aforementioned survey was conducted to gain general requirements from the industry [2]. Detailed requirements were elaborated by a processes analysis of the industrial partner in the consortium. Based on those, To-Be scenarios were derived which reflect optimal service processes [3]. Furthermore, a methodology was developed in order to analyze Service Cost Drivers in the service processes [4]. Resting upon these findings, the design of the IRM was constructed which addresses particularly Best-Practices and Performance Metrics [5].

Since the term Best-Practice is not strictly defined in the scientific community, Coordination Mechanisms and Collaboration Strategies were examined on detailed level in order to compile them to Best-Practices. First, Coordination Mechanisms and Collaboration Strategies were identified and adapted to the Service Domain [6]. Based on these findings, business processes were developed for the service processes 
and adequate information systems were designed [7]. Finally, they were evaluated quantitatively in order to get detailed information about their current use in practice. In the end, major findings were compiled in more than 100 Best-Practices.

In order to evaluate the service processes, a Performance Measurement System (PMS) was developed with according indicators. The progress of the development started with a comprehensive literature research of existing PMS [8]. The identified indicators were collected and aggregated into an innovative PMS for the service domain which addresses several perspectives such as the satisfaction of service provider and customer, the service object and the service delivery process. Altogether more than 300 indicators were collected that cover quality, time and cost dimensions [9].

The aforementioned Best-Practices and the PMS were developed in close cooperation with the industrial partners of the consortium. To ensure a high quality of the IRM, each of the business processes has to be standardized regularly according to the findings of the workpackages and to industrial experiences. To ensure a durable solution for these tasks, the Technical Steering Committee (TSC) was constituted with representatives of all research partners, SKF, H20 and Comau. In addition to the standardizing activities of the TSC, it is in charge of the acceptance of new processes in the IRM.

Summarizing, the IRM covers more than 100 Best-Practices, 300 indicators and covers service process for maintenance, packaging, logistics, retrofit and quality control. At the moment more than 50 process elements are developed so far for the IRM.

\section{The InCoCo-S Reference Model}

\subsection{Structure}

The IRM is structured hierarchically. On the first level, a reference guideline is given for superior activities of services. The second level offers business related adoptions of the Level 1 activities. The $3^{\text {rd }}$ and last level covers each of the Level 1 and Level 2 processes on a more detailed level of the service provider.

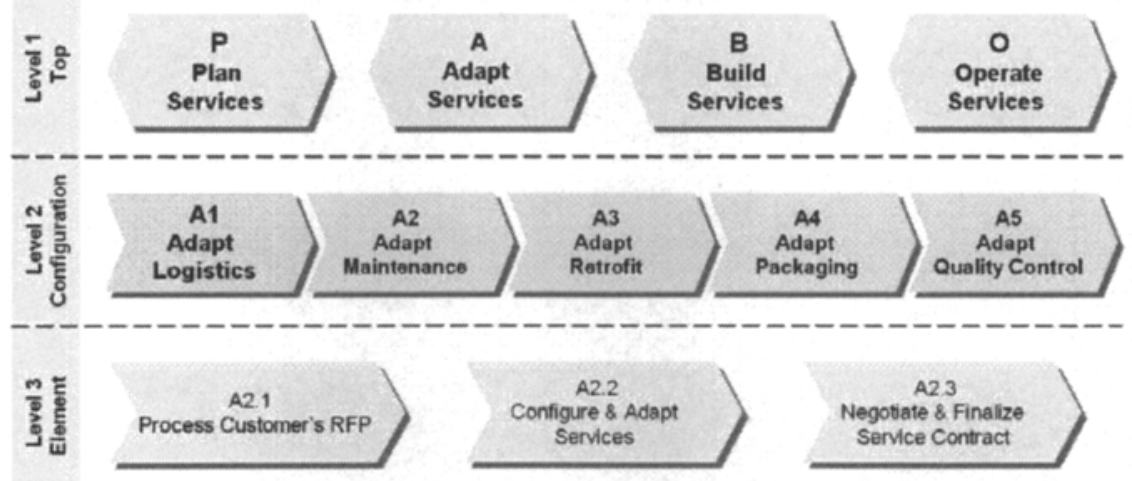




\section{Figure 3: Structure of the IRM}

The differentiation between Plan, Adapt, Build and Operate activities on level 1 is a basic feature of the IRM that is continued on each of the three Levels. Plan activities consist of preparatory work for Adapt, Build or Operate activities. Adapt activities address all processes from the customer inquiry to the signed service contract. Processes that have to do with resource allocation in order to prepare the service installation at the customer are defined as Build activities. Finally, Operate activities describe all processes along the service delivery.

\subsection{Process Interactions}

For each of the Adapt, Build and Operate activities, process interaction diagrams were elaborated which depict the available set of Level 3 processes as shown in figure 4.

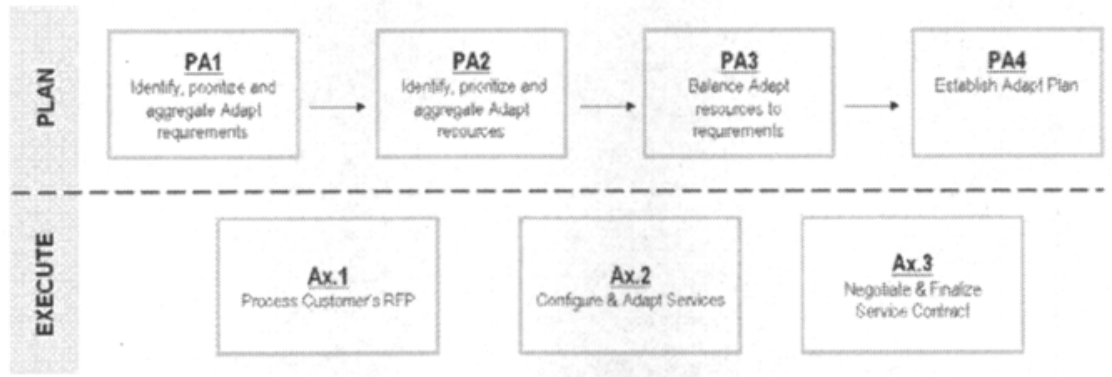

Figure 4: Plan Interaction diagram of the Adapt Phase of the IRM

The interaction diagram describes Level 3 processes for PLAN and EXECUTES activities. The PLAN activities cover all the processes that are necessary to create a service offer. Therefore, the customer requirements and the resources of the service provider are identified and priorized first. Afterwards, they will be matched with one another in order to establish a service plan. This plan is the basis for a service offer that will be given to the customer.

The EXECUTE activities encompassed value-added processes in the service supply chain. In the ADAPT Phase, these ones are defined as the Customer Inquiry, the Configuration of the Services for the Customer and the Negotiation und Finalizing of the Service Contract by both parties.

The Interaction Plan in figure 3 do not encompasses interdependencies of the EXECUTE activities to one another because these processes differ in every service organization. Hence, the IRM provides only a set of processes that have to be linked by every service organization by its own. 


\subsection{Process Elements}

Each of the process elements on Level 3 is described on a more detailed level by using a framework as shown in figure 3.

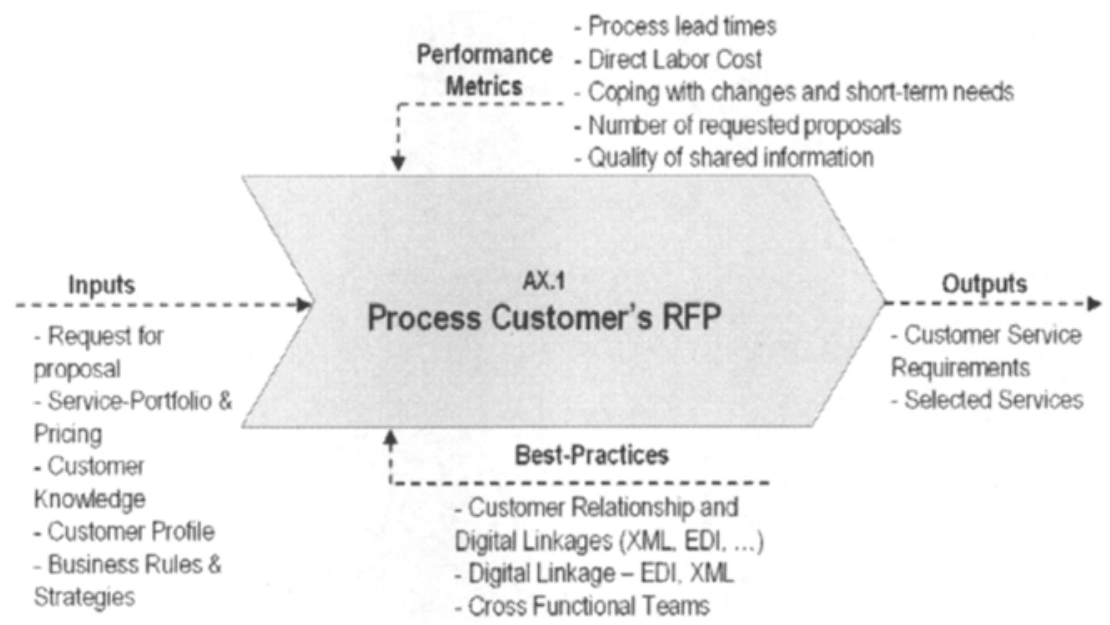

Figure 5: Process Elements on Level 3

The processes are specified by Inputs, Outputs, Performance Metrics and BestPractices. The analysis of Inputs and Outputs reveals interdependencies to other process elements that enable the Service Provider to reduce inherent complexity and thus to increase its effectively. Performance Metrics cover several indicators for the Service Provider to measure the performance of the services in terms of time, quality and costs. Finally, Best-Practices allow an easy adoption of proven methodologies.

\section{Practical Adaptation}

SKF is a leading provider of condition monitoring systems for bearings. Currently the company created a new service division to enlarge their activities in a growing market segment. To improve the service effectivity and efficiency of their service processes, SKF is implementing the IRM for their business processes. Figure 3 shows the interactions diagram of the IRM that was used as a starting point. 


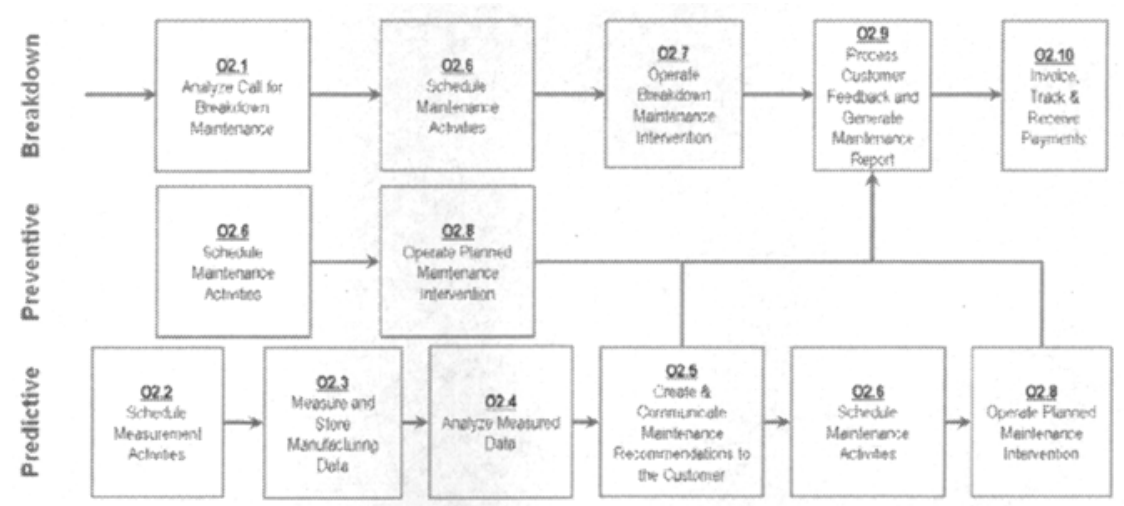

Figure 6: Interaction diagram for the Operate Phase for Maintenance Services

By modeling the business process in the service by using the IRM, SKF gains the possibility to define organization specific processes as shown figure 6 . In case of changing customer requirements, these processes can be changed easily with a high level of transparency. New processes can be added, abundant processes can de eliminated and the sequence of the processes can be switched if necessary.

Furthermore, the performance metrics allow a measurement of various dimensions of the service delivery. Therefore a benchmark between each of the conducted orders is possible as well as a focused optimization of the overall service performance.

Finally, the processes model according to the IRM helps a preparation for software implementation by aligning the business process requirements with IT systems. In that way, recent business processes can be standardized the internal \& external communication.

Comprising, SKF gains great advantages for their current business field that inherits great potential for further enlargement.

\section{Conclusion}

The IRM is an innovative approach to model business processes in the service domain. It provides great advantages for service departments in terms of aligned resources and information flows. Based on the principles of a supply chain, the IRM regards various kinds of information such as Inputs and Outputs, Best-Practices and Performance Metrics. A pilot implementation is being done for the new service division of SKF. Thus, SKF could identify further potential to improve the effectivity of their service processes as well as to align the IT Systems with the business process $\&$ further plan the personal resources for the new business.

During the next few months, the consortium will focus on developing further case studies with the industry outside the consortium to validate and implement the reference model. There are few ongoing validations where maintenance services are being offered by a collection of service providers. Such validations strengthen the model and make it applicable in generic to providers of industrial services. 
Companies operating in the domain of logistics, maintenance, packaging, modernization \& quality control are very much invited to participate in this validation exercise. Interested companies who want to join the validation activities should contact the InCoCo-S consortium at incoco@fir.rwth-aachen.de

\section{Literature}

[1] European Commission: The competitiveness of Business Related Services and their contribution to the performance of European enterprises. Final version released on $4^{\text {th }}$ of December

[2] DL2.1 - Consolidated Supply Chain \& Service Providers Survey Results

[3] DL2.4"As Is" Business Use Cases \& Requirement Specification in the Service-Supply Chain domain for all the 4 business cases

[4] DL2.6 Design of S-SCOR Framework Structure

[5] DL3.1 Design of coordination mechanisms \& collaboration strategies

[6] DL3.2 Development of business processes for service - supply chain

[7] DL4.1 Formulation of the MoP for service - supply chain

[8] DL4.2 Methodology to Measure the Performance of Systems and Development of Tools to quantify added value and to determine market pricing for different services 